\title{
Heats of transport from diffusion thermoeffect measurements on binary liquid mixtures of carbon tetrachloride with benzene, toluene, 2-propanone, n-hexane, and n-octane
}

Richard L. Rowley

rowley@byu.edu

S. C. Yi

Follow this and additional works at: https://scholarsarchive.byu.edu/facpub

Part of the Chemical Engineering Commons

\section{Original Publication Citation}

Yi, S. C. and R. L. Rowley. "Heats of transport from diffusion thermoeffect measurements on binary liquid mixtures of carbon tetrachloride with benzene, toluene, 2-propanone, n-hexane, and n-octane." The Journal of Chemical Physics 87 (1987): 728-7213

\section{BYU ScholarsArchive Citation}

Rowley, Richard L. and Yi, S. C., "Heats of transport from diffusion thermoeffect measurements on binary liquid mixtures of carbon tetrachloride with benzene, toluene, 2-propanone, n-hexane, and n-octane" (1987). Faculty Publications. 742.

https://scholarsarchive.byu.edu/facpub/742

This Peer-Reviewed Article is brought to you for free and open access by BYU ScholarsArchive. It has been accepted for inclusion in Faculty Publications by an authorized administrator of BYU ScholarsArchive. For more information, please contact ellen_amatangelo@byu.edu. 


\title{
Heats of transport from diffusion thermoeffect measurements on binary liquid mixtures of carbon tetrachloride with benzene, toluene, 2-propanone, $n$-hexane, and $n$-octane
}

\author{
S. C. Yi and R. L. Rowley \\ Department of Chemical Engineering, Brigham Young University, Provo, Utah 84602
}

(Received 13 July 1987; accepted 26 August 1987)

\begin{abstract}
Measurements of heats of transport are reported for binary liquid mixtures containing carbon tetrachloride and benzene, toluene, 2-propanone, $n$-hexane, or $n$-octane at $298 \mathrm{~K}$ and ambient pressure. Additionally, measurements were made at $308 \mathrm{~K}$ for carbon tetrachloride with benzene, toluene, and 2-propanone. The corresponding heat-mass Onsager coefficients are also reported, from which thermal diffusion ratios have been calculated based on Onsager reciprocity. These data will be used in a companion paper to report a modified Enskog method for correlation and prediction of heats of transport.
\end{abstract}

\section{INTRODUCTION}

Not only will a temperature gradient give rise to a heat flux in fluid mixtures, but so also will composition gradients (more appropriately, isothermal chemical potential gradients). This latter effect, known as the diffusion thermoeffect or the Dufour effect, is characterized by a transport property called the heat of transport. The heat of transport of component $i, Q_{i}^{*}$, relates the magnitude of the produced heat flux to the diffusional flux of component $i$ under isothermal conditions. For many years the diffusion thermoeffect was thought to be too small for measurement in liquid mixtures because thermal conduction opposes build up of the massflux-induced temperature gradient and because heats of mixing were thought to obscure the effect. Ingle and Horne showed mathematically that the diffusion thermoeffect should be measurable in carefully designed experiments and Rowley and Horne ${ }^{2}$ were able to measure heats of transport in carbon tetrachloride + cyclohexane mixtures accurately enough to verify Onsager reciprocity. Subsequently, Rowley and co-workers have used the diffusion thermoeffect to measure heats of transport in ideal liquid mixtures, ${ }^{3,4}$ ternary liquid mixtures, ${ }^{5}$ and recently in nonideal liquid mixtures. ${ }^{6}$ These studies have shown that while it is true that measured temperature gradients induced in initially isothermal liquid mixtures are small due to opposition by thermal conduction, the heat of transport itself may be large. As heats of transport contain significant information concerning the actual energy-diffusional relationship of molecular interactions, their measurement is of interest; values obtained may enhance our understanding and development of generalized molecular transport models and theories.

Previous studies of the diffusion thermoeffect have focused on development and verification of the method for accurate determination of liquid mixture heats of transport. ${ }^{1,2,7}$ Most of the mixtures studied were nearly ideal in the thermodynamic sense. Recently, Rowley et $a l^{6}{ }^{6}$ published results of six nonideal mixtures containing carbon tetrachloride and a paraffin. In this work we report binary measurements made on nonideal systems containing carbon tetrachloride and either an aromatic or ketone constituent with emphasis on the composition dependence of the heat of transport. These two studies provide sufficient data that preliminary testing of models may begin. In the companion paper to this one, we present a simple revision to the squarewell Enskog model and test its predictive and correlational capabilities.

\section{EXPERIMENTAL}

All chemicals used in this study were specified by the manufacturer to be $99+\%$ pure and were used without further purification. Mixtures were prepared gravimetrically in glass-stoppered flasks.

The diffusion thermoeffect technique for measurement of heats of transport was utilized in this study. As before, the cell was a modification of the boundary-sharpening or Tiselius diffusion cell. The cell and experimental technique were the same as those used previously and are adequately described elsewhere. ${ }^{5,6}$ For clarity of discussion, only the basic principles of the experiment are repeated here. To measure the heat of transport of a binary mixture of mean mass fraction $w_{1}$, two mixtures of different compositions (such that the average composition is $w_{1}$ ) are used to create an initial interface in the bore of a large stopcock. Subsequently, the interface is lowered into the cell and sharpened by withdrawal of fluid at cell half-height. Because the withdrawal rate is faster than diffusion, the sharpened interface is stable until the pumps are turned off at the start of the experiment. Temperature differences between two tiny thermocouples, located equidistant above and below the interface, are monitored as a function of time. Temperature differences rather than absolute temperatures were used in accordance with the studies of Ingle and Horne, ${ }^{1}$ which show that heat of mixing effects provide less background response in this mode, and to eliminate the need for a thermocouple reference since one thermocouple can be referenced to the other. Initial nonuniformities in fluid temperature have been shown ${ }^{4-6}$ not to interfere with the analysis procedure for data obtained subsequent to the first $800 \mathrm{~s}$ of the experiment. The $\Delta T$ vs time data are logged at $100 \mathrm{~s}$ intervals over the normal $7200 \mathrm{~s}$ duration of the experiment and subsequently analyzed to obtain the heats of transport. 
TABLE I. Thermophysical properties of the pure components.

\begin{tabular}{|c|c|c|c|c|c|c|c|}
\hline $\begin{array}{l}\text { A. Equations } \\
\text { property }\end{array}$ & & & Equatic & & & & Units \\
\hline $\begin{array}{l}\text { Molar volume (Ref. 8) } \\
\text { Heat capacity (Ref. 8) } \\
\text { Thermal conductivity (Ref. 9) }\end{array}$ & & & $\begin{array}{l}V=A+ \\
C_{p}=C \\
k=F\end{array}$ & $\begin{array}{l}B T \\
+D T+E \\
G T\end{array}$ & & & $\begin{array}{l}\mathrm{cm}^{3} / \mathrm{mol} \\
\mathrm{J} / \mathrm{mol} \mathrm{K} \\
\mathrm{mW} / \mathrm{m} \mathrm{K}\end{array}$ \\
\hline $\begin{array}{c}\text { B. Constants } \\
\text { component }\end{array}$ & $A$ & $B$ & $C$ & $D$ & $10^{3} \cdot E$ & $F$ & $G$ \\
\hline Carbon tetrachloride & 62.39 & 0.116 & 47,07 & 0.530 & -0.8 & 163.60 & -0.218 \\
\hline Benzene & 57.80 & 0.106 & 83.96 & 0.112 & 0.2 & 238.70 & -0.323 \\
\hline Toluene & 72.55 & 0.115 & 41.93 & 0.540 & -0.5 & 216.26 & -0.292 \\
\hline 2-Propanone & 43.61 & 0.102 & 243.25 & -0.975 & 2.0 & 308.66 & -0.502 \\
\hline$n$-Hexane & 79.10 & 0.176 & 266.48 & -0.820 & 2.0 & 217.79 & -0.328 \\
\hline$n$-Octane & 108.46 & 0.185 & 194.80 & -0.004 & 0.7 & 208.56 & -0.277 \\
\hline
\end{tabular}

\section{ANALYSIS PROCEDURE}

As before $e^{2-4}$ a numerical procedure was used to solve the partial differential equations describing the diffusion thermoeffect with isothermal initial and vanishing flux boundary conditions. The corresponding composition and temperature equations, simplified ${ }^{1}$ for the cell geometry, types of fluids being studied, and experimental arrangement, are

$$
\begin{aligned}
\rho\left(\frac{\partial w_{1}}{\partial t}\right)=\{ & \left.\frac{\partial\left[\rho D\left(\partial w_{1} / \partial z\right)\right]}{\partial z}\right\} \\
\rho C_{P}\left(\frac{\partial T}{\partial t}\right)= & \left\{\frac{\partial[k(\partial T / \partial z)]}{\partial z}\right\}+\left\{\frac{\partial\left[\rho D Q_{1}^{*}\left(\partial w_{1} / \partial z\right)\right]}{\partial z}\right\} \\
& +\left[\frac{\rho D M^{3}}{\left(M_{1} M_{2}\right)^{2}}\right]\left(\frac{\partial^{2} H^{E}}{\partial x_{1}^{2}}\right)\left(\frac{\partial w_{1}}{\partial z}\right)^{2},
\end{aligned}
$$

where $\rho$ is density, $C_{P}$ is specific heat, $k$ is thermal conductivity, $D$ is mutual diffusivity, $M$ is mean molecular weight of the mixture, $M_{i}$ is molecular weight of component $i, x_{1}$, is mole fraction of component 1 , and $H^{E}$ is the molar excess enthalpy. A Crank-Nicholson technique was used and the numerical solution was integrated into a nonlinear, weight- ed, least-squares fitting program which allowed determination of $Q_{1}^{*}$ from the measured temperature differences (at fixed and known thermocouple locations) as a function of time. Temperatures calculated at the grid points corresponding to the locations of the centers of the thermocouple beads and at times corresponding to measured times were subtracted from each other. Experimental temperature differences were used to adjust $Q_{1}^{*}$ until a minimum in the sum of the squares of the residuals was obtained.

Also required in the analysis are the values of the thermophysical properties appearing in Eqs. (1) and (2). Table I contains relations used to compute the pure component properties which were then used in conjunction with the mixture relations given in Table II to compute the thermophysical properties at each grid point composition in the numerical solution. Only the mean temperature of the run was used in the evaluation of the properties since the induced temperature profiles are small (less than $\pm 0.3 \mathrm{~K}$ deviation from the initial value) and lead to insignificant changes in property values. This also serves to decouple Eq. (1) from Eq. (2), allowing solution of the composition equation at each time row, independent of the temperature equation so-

TABLE II. Thermophysical properties for mixtures.

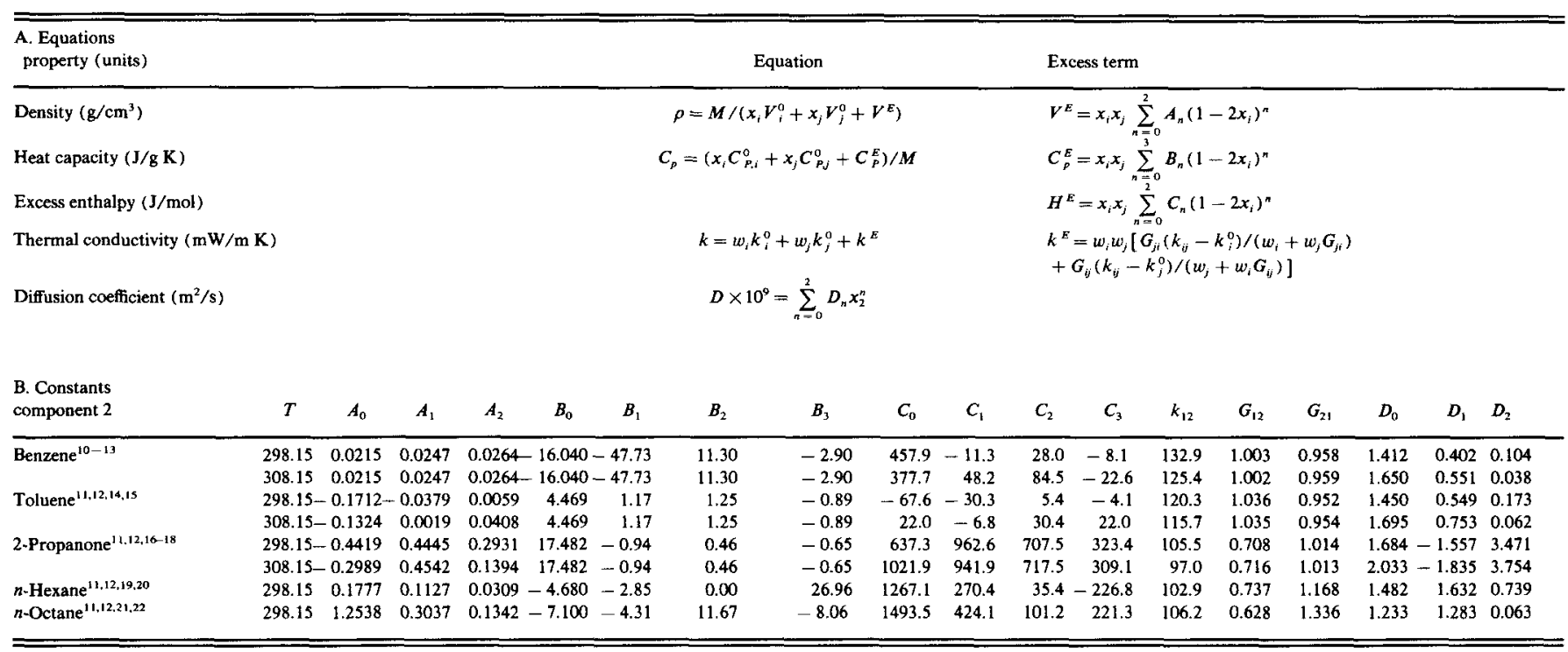


lution. Because the relaxation time of diffusion is slow compared to that of thermal conduction, the composition profile of the previous time step could be used in the temperature solution without loss of accuracy. Initially, very short time steps $(2 \mathrm{~s})$ were used when the composition gradient was steep. These were gradually expanded to $100 \mathrm{~s}$ steps as the composition gradient was diminished.

\section{RESULTS}

The heats of transport of carbon tetrachloride obtained in this study are shown in Table III. A Monte Carlo error analysis program was developed to determine the expected precision of the heats of transport. One thousand replicated runs, generated by including random normal deviate errors based on the uncertainty of each of the experimental variables, were analyzed in the same manner as the actual experimental data. To minimize computer CPU time, the analytical approximate solutions to Eqs. (1) and (2) by Ingle and Horne $^{1}$ were used in these simulations rather than the complete numerical solution used in the actual data analysis.
Using the following uncertainties in measured and input variables, $\pm 2.6 \mathrm{mK}$ in $T, \pm 1 \%$ in $\rho, \pm 4 \%$ in $D, \pm 1 \%$ in $C_{P}$, and $\pm 4 \%$ in $k$, we obtained an uncertainty in fitted heats of transport of about $\pm 4 \%$. Nearly $\pm 1.6 \%$ of this results from uncertainties in the measured temperature. $A$ worst possible case analysis indicated a maximum possible error of about $\pm 9 \%$. Since the Monte Carlo simulations do not account for possible experimental and procedural errors, we estimate $\pm 5 \%$ to be the experimental precision. Rowley and Horne, ${ }^{2}$ using a different type of cell, were able to obtain heats of transport which agreed within $\pm 2 \%$ of values obtained from thermal diffusion data, but we estimate the accuracy of the results here at about $\pm 6 \%$. Replicate experiments were performed on the carbon tetrachloride + benzene and $n$-hexane systems to experimentally test the reproducibility of the measurements. The replicates were all within $\pm 2.9 \%$ of the mean values.

Thermal diffusion factors $\alpha$ are indications of the degree of separation that can be achieved by thermal diffusion. Heats of transport and thermal diffusion factors are not independent, but are directly related by Onsager reciprocity,

TABLE III. Heats of transport of carbon tetrachloride (1) in mixtures at ambient pressure.

\begin{tabular}{|c|c|c|c|c|c|c|c|}
\hline Comp. \#2 & $T(\mathbf{K})$ & $w_{1}$ & $x_{1}$ & $Q_{\mathrm{i}}^{*}(\mathrm{~kJ} / \mathrm{kg})$ & $1+\Gamma_{11}$ & $10^{7} \cdot \Omega_{10}(\mathrm{~kg} / \mathrm{ms})$ & $\alpha$ \\
\hline \multirow[t]{10}{*}{ Benzene } & 298.15 & 0.1 & 0.0534 & 22.6 & 0.985 & 2.101 & 2.409 \\
\hline & 298.15 & 0.3 & 0.1787 & 28.5 & 0.959 & 6.042 & 2.249 \\
\hline & 298.15 & 0.5 & 0.3368 & 30.5 & 0.940 & 7.370 & 1.698 \\
\hline & 298.15 & 0.7 & 0.5423 & 31.5 & 0.935 & 5.930 & 1.159 \\
\hline & 298.15 & 0.9 & 0.8205 & 33.9 & 0.965 & 2.384 & 0.742 \\
\hline & 308.15 & 0.1 & 0.0534 & 22.8 & 0.987 & 2.367 & 2.348 \\
\hline & 308.15 & 0.3 & 0.1787 & 29.1 & 0.959 & 6.922 & 2.221 \\
\hline & 308.15 & 0.5 & 0.3368 & 31.7 & 0.941 & 8.626 & 1.707 \\
\hline & 308.15 & 0.7 & 0.5423 & 32.0 & 0.937 & 6.788 & 1.137 \\
\hline & 308.15 & 0.9 & 0.8205 & 34.9 & 0.966 & 2.759 & 0.739 \\
\hline \multirow[t]{10}{*}{ Toluene } & 298.15 & 0.1 & 0.0624 & 20.5 & 1.000 & 2.104 & 1.879 \\
\hline & 298.15 & 0.3 & 0.2043 & 25.2 & 0.993 & 5.803 & 1.789 \\
\hline & 298.15 & 0.5 & 0.3746 & 26.9 & 0.986 & 7.037 & 1.444 \\
\hline & 298.15 & 0.7 & 0.5829 & 29.0 & 0.980 & 6.008 & 1.140 \\
\hline & 298.15 & 0.9 & 0.8453 & 32.3 & 0.983 & 2.645 & 0.889 \\
\hline & 308.15 & 0.1 & 0.0624 & 21.0 & 0.999 & 2.395 & 1.864 \\
\hline & 308.15 & 0.3 & 0.2043 & 25.9 & 0.993 & 6.672 & 1.780 \\
\hline & 308.15 & 0.5 & 0.3746 & 27.4 & 0.986 & 8.072 & 1.423 \\
\hline & 308.15 & 0.7 & 0.5829 & 29.9 & 0.980 & 7.002 & 1.138 \\
\hline & 308.15 & 0.9 & 0.8435 & 33.1 & 0.983 & 3.052 & 0.881 \\
\hline \multirow[t]{10}{*}{ 2-Propanone } & 298.15 & 0.1 & 0.0403 & 25.1 & 0.955 & 3.852 & 3.561 \\
\hline & 298.15 & 0.3 & 0.1393 & 27.3 & 0.849 & 9.193 & 2.842 \\
\hline & 298.15 & 0.5 & 0.2741 & 27.9 & 0.726 & 10.284 & 2.064 \\
\hline & 298.15 & 0.7 & 0.4684 & 30.0 & 0.594 & 8.292 & 1.491 \\
\hline & 298.15 & 0.9 & 0.7726 & 33.2 & 0.582 & 3.044 & 0.798 \\
\hline & 308.15 & 0.1 & 0.0403 & 26.1 & 0.955 & 4.211 & 3.583 \\
\hline & 308.15 & 0.3 & 0.1393 & 28.4 & 0.852 & 10.103 & 2.853 \\
\hline & 308.15 & 0.5 & 0.2741 & 28.8 & 0.729 & 11.363 & 2.054 \\
\hline & 308.15 & 0.7 & 0.4684 & 30.5 & 0.601 & 9.187 & 1.451 \\
\hline & 308.15 & 0.9 & 0.7726 & 34.3 & 0.595 & 3.528 & 0.780 \\
\hline \multirow[t]{5}{*}{$n$-Hexane } & 298.15 & 0.1 & 0.0586 & 25.9 & 0.985 & 3.588 & 2.545 \\
\hline & 298.15 & 0.3 & 0.1936 & 33.0 & 0.948 & 10.259 & 2.522 \\
\hline & 298.15 & 0.5 & 0.3591 & 36.8 & 0.900 & 12.980 & 2.150 \\
\hline & 298.15 & 0.7 & 0.5666 & 44.5 & 0.849 & 12.233 & 1.925 \\
\hline & 298.15 & 0.9 & 0.8345 & 55.8 & 0.855 & 5.415 & 1.594 \\
\hline \multirow[t]{5}{*}{$n$-Octane } & 298.15 & 0.1 & 0.0762 & 19.6 & 1.003 & 1.942 & 1.510 \\
\hline & 298.15 & 0.3 & 0.2414 & 28.0 & 1.000 & 6.324 & 1.839 \\
\hline & 298.15 & 0.5 & 0.4262 & 34.1 & 0.980 & 9.048 & 1.923 \\
\hline & 298.15 & 0.7 & 0.6341 & 41.0 & 0.925 & 9.278 & 2.042 \\
\hline & 298.15 & 0.9 & 0.8699 & 52.8 & 0.858 & 5.196 & 2.333 \\
\hline
\end{tabular}


$\Omega_{10}=\Omega_{01}$. The Onsager heat-mass coefficient $\Omega_{01}$ can be calculated from ${ }^{5}$

$$
\Omega_{01}=\rho D Q_{1}^{*} M_{1} M_{2} w_{1} w_{2} /\left[M R T\left(1+\Gamma_{11}\right)\right],
$$

where $\Gamma_{11}$ is the so-called thermodynamic factor, related to the activity coefficient of component $1, \gamma_{1}$, by

$$
\Gamma_{11}=\left(\frac{\partial \ln \gamma_{1}}{\partial \ln x_{1}}\right)_{T, P}
$$

Values of $\Gamma_{11}$ were obtained from activity coefficient data ${ }^{12}$ in accordance with the above two equations and are compiled in Table III. The coefficient $\Omega_{10}$ can be related to the thermal diffusion factor by

$$
\Omega_{10}=\rho D \alpha x_{1} x_{2} .
$$

Equating Eqs. (3) and (5) on the basis of Onsager reciprocity yields

$$
\alpha=Q_{1}^{*}\left(M_{1} M_{2}\right)^{2} /\left[M^{3} R T\left(1+\Gamma_{11}\right)\right] .
$$

Values of $\alpha$ obtained from the measured heats of transport in conjunction with Eq. (6) are also given in Table III.

Story and Turner ${ }^{23}$ also reported thermal diffusion factors on this system measured in a flow thermal diffusion cell at the same temperatures reported here. Their results are compared to ours in Fig. 1. Agreement is acceptable at compositions below $50 \mathrm{~mol} \%$ carbon tetrachloride, but deviate significantly at higher compositions. They only made one measurement at $308.15 \mathrm{~K}$, but the very slight decrease in thermal diffusion factor with an increase in temperature is in agreement with our results. Guczi and Tyrrell ${ }^{24}$ have also reported thermal diffusion factors at $298.15 \mathrm{~K}$, their results are also shown in Fig. 1. Again agreement in the lower carbon tetrachloride composition range is not terrific, but acceptable. Drickamer et al. ${ }^{25}$ reported values at $313 \mathrm{~K}$. Although this does not correspond to the temperature for the data reported here, our results indicate very little temperature dependence for $\alpha$ and so a direct comparison is not unreasonable. As shown in Fig. 1 there is considerable dis-

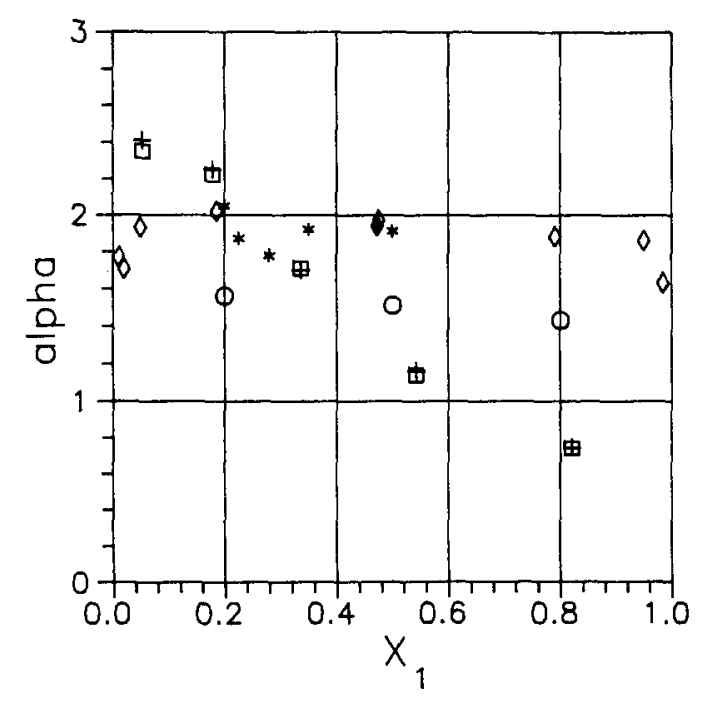

FIG. 1. Thermal diffusion factor $\alpha$ for carbon tetrachloride (1) + benzene mixtures determined in this study $(+, 298.15 \mathrm{~K} ; \square, 308.15 \mathrm{~K})$ compared to values reported in Ref. $23(\diamond, 298.15 \mathrm{~K} ; 308.15 \mathrm{~K})$, Ref. $24(*, 298.15$ $\mathrm{K})$, and Ref. $25(\mathrm{O}, 313 \mathrm{~K})$. agreement and scatter between all four of the data sets except in the region between $x_{1}=0.2$ and $x_{1}=0.4$. Our data show a stronger composition dependence over the entire composition range than the others. Story and Turner, on the other hand, show a rapid decrease in $\alpha$ near the pure component limits.

\section{DISCUSSION OF RESULTS}

It is of interest to plot the heats of transport as a function of composition to ascertain the possibility of obtaining a pure component value for the heat of transport of carbon tetrachloride independent of which system the value was determined from. Rather than plot $Q_{1}^{*}$, we choose to plot $M Q_{1}^{*}$ in Figs. 2 and 3 because we find it to be more linear in mole fraction. Values of $M Q_{1}^{*}$ were fitted to a second-order polynomial equation in mole fraction using a least-squares regression program; the equation and resultant coefficients are shown in Table IV. The smoothing curves represented by these equations are the lines given in Fig. 2 at $298.15 \mathrm{~K}$ and in Fig. 3 at $308.15 \mathrm{~K}$.

From Fig. 2 it is obvious that $Q_{1}^{*}$ in the pure carbon tetrachloride limit is not the same for the five systems. Within the experimental uncertainty, benzene, toluene, and 2propanone yield the same value while the two paraffins yield a different value. The infinite dilution values for $Q_{1}^{*}$ are remarkably similar for all the systems studied. Since for a binary system $Q_{2}^{*}=-Q_{1}^{*}$, this infinite dilution value represents the pure component limit for the second component. Further studies are mandated to test this observation on other groups of mixtures (each group containing a different common component). If similar results are found for those groups, it may by possible to develop a predictive technique based on tabulated infinite dilution values.

While the observed temperature dependence of the heats of transport is small, it is definitely shown that $Q_{1}^{*}$, decreases with increasing temperature. This trend is more

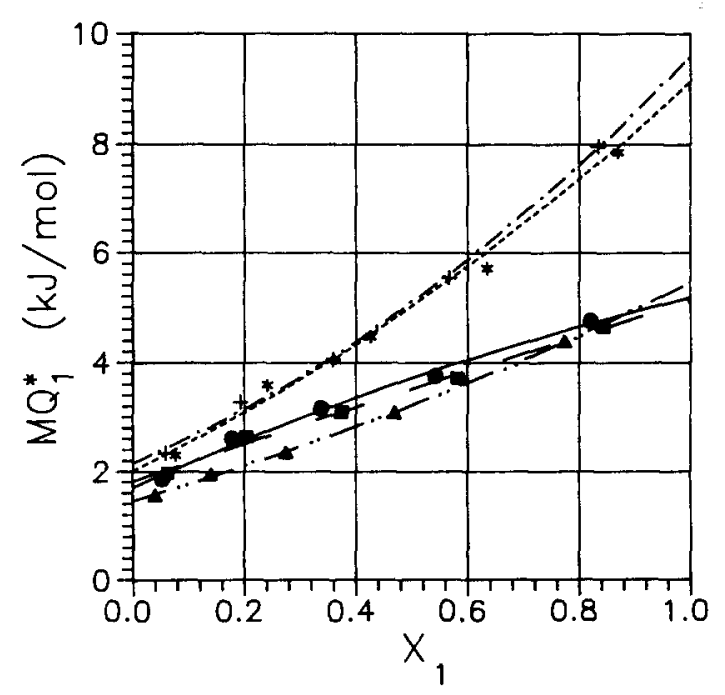

FIG. 2. Product of mean molecular weight and heat of transport at 298.15 $\mathrm{K}$ for carbon tetrachloride (1) and benzene $(-; \bullet)$, toluene $(--; \mathbf{})$, acetone benzene $(-\cdots-;), n$-hexane $(-\cdots ;+)$, and $n$-octane $(-\cdots ; *)$. 


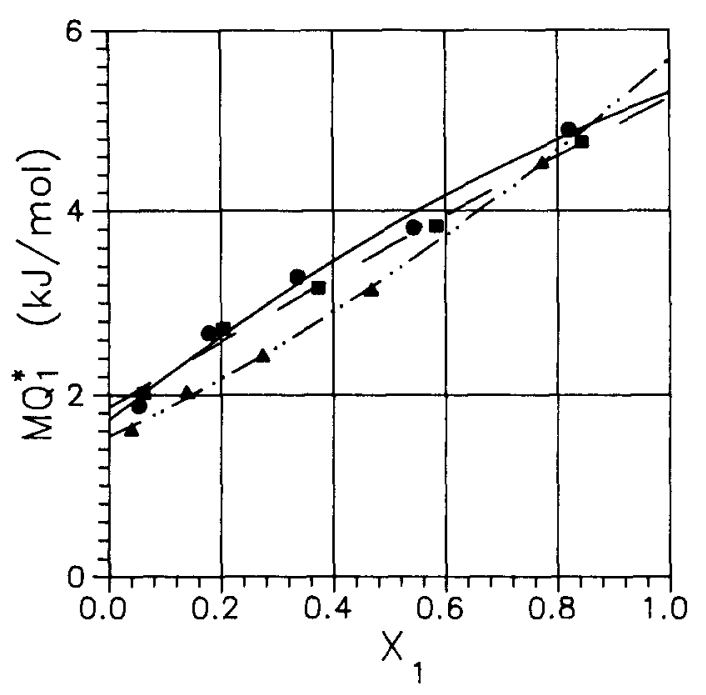

FIG. 3. Product of mean molecular weight and heat of transport at 308.15 $\mathrm{K}$ for carbon tetrachloride $(1)$ and benzene $(-; 0)$, toluene $(--; \mathbf{\square})$, and acetone $(-\cdots ; \boldsymbol{A})$.

observable in terms of the Onsager coefficients illustrated in Fig. 4.

\section{CONCLUSIONS}

Diffusion thermoeffect measurements have been made at 298.15 and $308.15 \mathrm{~K}$ for carbon tetrachloride plus benzene, toluene, and 2-propanone mixtures and at $298.15 \mathrm{~K}$ for carbon tetrachloride plus $n$-hexane and $n$-octane mixtures. From comparison of these $\Delta T$ vs $t$ measurements to the numerical solution of the appropriate diffusion thermoeffect boundary value problem, heats of transport have been regressed. Calculation of Onsager coefficients and thermal diffusion factors was also carried out using activity coefficient information. Measured heats of transport are considered to be reproducible to about $\pm 5 \%$ as supported by Monte Carlo error analysis procedures and limited replicate studies. Accuracy is assumed to be about $\pm 6 \%$, although calculated thermal diffusion factors do not agree with previous literature values within the combined specified accuracy limits, except in the range of $x_{1}=0.2$ to $x_{1}=0.4$. However, none of the previous data sets are in agreement outside of this composition range.

TABLE IV. Coefficients for the smoothing equation $Q_{1}^{*} M=\Sigma_{n=0}^{2} Q_{n} x_{1}^{n}$ $(\mathrm{kJ} / \mathrm{mol})$ for mixtures of the indicated component with carbon tetrachloride (1) at ambient pressure.

\begin{tabular}{lccccc}
\hline \hline Comp. \#2 & $T(\mathrm{~K})$ & $Q_{0}$ & $Q_{1}$ & $Q_{2}$ & AAD (\%) \\
\hline Benzene & 298.15 & 1.702 & 4.599 & -1.126 & 2.9 \\
& 308.15 & 1.719 & 4.821 & -1.233 & 3.5 \\
Toluene & 298.15 & 1.813 & 3.502 & -0.203 & 2.1 \\
& 308.15 & 1.860 & 3.609 & -0.222 & 2.2 \\
2-Propanone & 298.15 & 1.457 & 3.071 & 0.923 & 1.0 \\
& 308.15 & 1.539 & 2.900 & 1.242 & 1.3 \\
n-Hexane & 298.15 & 2.163 & 4.281 & 3.153 & 2.3 \\
$n$-Octane & 298.15 & 2.030 & 4.712 & 2.177 & 2.9 \\
& & & & & \\
\hline
\end{tabular}

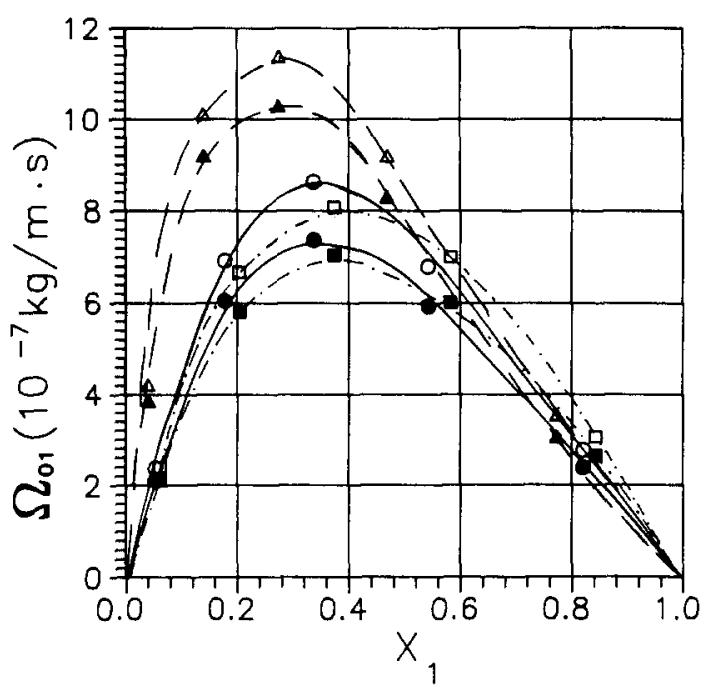

FIG. 4. Onsager coefficient $\boldsymbol{\Omega}_{01}$ for carbon tetrachloride (1) and benzene $(-; O)$, toluene $(-\cdots ; \square)$, and acetone $(-; \Delta)$. Open symbols are for 298.15 $\mathrm{K}$; closed for $308.15 \mathrm{~K}$.

The results show that heats of transport decrease with increasing temperature. Furthermore, it appears that all five systems yield approximately the same value for the infinite dilution value of the heat of transport of carbon tetrachloride. While the pure component limit of the heat of transport of carbon tetrachloride is similar for mixtures containing benzene, toluene, and 2-propanone, it differs that from that found for $n$-hexane and $n$-octane. It is hoped that these data will form the start of a data base from which models and theories for the heat of transport may be developed and tested. To this end, we present in a subsequent, but related, paper a revision to the square-well Enskog theory which is able to correlate the data well with one interaction coefficient or predict the data adequately with no mixture adjustable parameters.

\section{ACKNOWLEDGMENT}

Support of this project under National Science Foundation Grant No. CBT-85-1424 is gratefully acknowledged.

${ }^{1}$ S. E. Ingle and F. H. Horne, J. Chem. Phys. 59, 5582 (1973).

${ }^{2}$ R. L. Rowley and F. H. Horne, J. Chem. Phys. 68, 325 (1978).

${ }^{3}$ R. L. Rowley and F. H. Horne, J. Chem. Phys. 72, 131 (1980).

${ }^{4}$ R. L. Rowley and M. D. Hall, J. Chem. Phys. 85, 3550 (1986).

${ }^{5}$ G. Platt, T. Vongvanich, and R. L. Rowley, J. Chem. Phys. 77, 2121 (1982).

${ }^{6}$ R. L. Rowley, S. C. Yi, V. Gubler, and J. M. Stoker, Fluid Phase Equilib. (in press).

${ }^{7}$ G. Platt, T. Vongvanich, and R. L. Rowley, J. Chem. Phys. 77, 2113 (1982).

${ }^{8} \mathrm{~J}$. Timmermans, Physico-chemical Constants of Pure Organic Compounds (Elsevier, New York, 1950), Vols. 1 and 2.

${ }^{9}$ D. T. Jamieson, J. B. Irving, and J. S. Tudhope, Liquid Thermal Conductivity: A Data Survey to 1973 (HMO, Edinburgh, 1975).

${ }^{10} \mathrm{G}$. A. Bottomley and R. L. Scott, J. Chem. Thermodyn. 6, 973 (1974).

${ }^{1}$ C. Christensen, J. Gmehling, P. Rasmussen, and U. Weidlich, Heats of Mixing Data Collection (Dechema, Frankfurt, 1984).

${ }^{12} \mathrm{~J}$. Gmehling and U. Onken, Vapor-Liquid-Equilibrium Data Collection: Dechema Chem. Data Series, Vol. 1 (Verlag and Druckerel Friedrich Bischoff, Frankfurt, 1977).

${ }^{13}$ C. A. Caldwell and A. L. Babb, J. Phys. Chem. 60, 51 (1956). 
${ }^{14}$ R. P. Rastogi, J. Nath, and J. Misra, J. Phys. Chem. 43, 4179 (1965).

${ }^{15}$ R. K. Ghai and F. A. L. Dullien, J. Phys. Chem. 78, 2283 (1974).

${ }^{16}$ R. K. Nigam, B. S. Mahl, and P. P. Singh, J. Chem. Thermodyn. 4, 41 (1972).

${ }^{17} \mathrm{~J}$. J. Christensen, R. W. Hanks, and R. M. Izatt, Handbook of Heats of Mixing (Wiley, New York, 1982).

${ }^{18}$ D. K. Anderson, J. R. Hall, and A. L. Babb, J. Phys. Chem. 62, 404 (1958).

${ }^{19}$ T. G. Bissel, G. E. Okator, and A. G. Williamson, J. Chem. Thermodyn.
3, 393 (1971).

${ }^{20}$ D. L. Bidlack and D. K. Anderson, J. Phys. Chem. 68, 3790 (1964).

${ }^{21}$ D. V. S. Jain, B. S. Lark, S. S. Chamak, and P. Chander, Ind. J. Chem. 8, 66 (1970).

${ }^{22}$ G. D. Wedlake and F. A. L. Dullien, J. Chem. Eng. Data 19, 229 (1974). ${ }^{23}$ M. J. Story and J. C. R. Turner, Trans. Faraday Soc. 65, 349 (1965).

${ }^{24}$ L. Guczi and H. J. V. Tyrrell, J. Chem. Soc. 1965, 6577.

${ }^{25}$ H. G. Drickamer, L. T. Tichachek, W. S. Kmak, J. Phys. Chem. 60, 660 (1956). 